\title{
Post-treatment work patterns amongst survivors of lymphoma treated with high- dose chemotherapy with autologous stem- cell transplantation
}

Kjersti Helene Hernæs ${ }^{1,5^{*}}$, Knut B. Smeland ${ }^{2}$, Unn-Merete Fagerli ${ }^{3,4}$ and Cecilie E. Kiserud ${ }^{2}$

\begin{abstract}
Background: This study describes post-treatment work patterns in lymphoma survivors treated with high-dose chemotherapy with autologous stem-cell transplantation (HDT-ASCT). It aims to identify determinants for labour force participation and exclusion after HDT-ASCT.

Methods: All survivors treated with HDT-ASCT for lymphoma in Norway between 1995 and 2008, aged $\geq 18$ years at HDT-ASCT and alive at survey in 2012-2013 were eligible. We divide survivors by current employment status (fulltime, part-time and unemployed). Main outcomes are current employment status, work hours and work ability. Withdrawals are patients employed when diagnosed but not before HDT-ASCT.

Results: Of the 274 who completed the survey, $82 \%(N=225)$ were included in the final analyses. Mean age at survey was 52 years, 39\% were female, $85 \%$ were employed when diagnosed, $77 \%$ before HDT-ASCT and $69 \%$ at survey. Employment before HDT-ASCT corresponds with a higher probability of employment at survey for a given symptom burden. In the most extensive statistical model, it increases with 37.3 percentage points. Work hours amongst withdrawals plummet after HDT-ASCT while work ability shows a rebound effect. The potential economic gain from their re-enter into the work force equals $70 \%$ of the average annual wage in Norway in 2012.

Conclusions: For a given symptom burden, staying employed throughout diagnosis and treatment is associated with a higher probability of future employment. These results favour policies for labour force inclusion past diagnosis and treatment increasing cancer survivors' probability of future employment. However, we need more research on withdrawal mechanisms, and on policy measures that promote inclusion.
\end{abstract}

Keywords: Lymphoma, HDT-ASCT, Late effects, Employment, Work ability, Withdrawal

\footnotetext{
* Correspondence: KjerstiHelene.Hernaes@fhi.no

${ }^{1}$ Norwegian Institute of Public Health, PO Box 222, Skøyen, N-0213 Oslo,

Norway

${ }^{5}$ Previous affiliation: Research Support Services, Oslo University Hospital, Sogn

Arena, Klaus Torgårds vei 3, 3. Floor, 0372 Oslo, Norway

Full list of author information is available at the end of the article
}

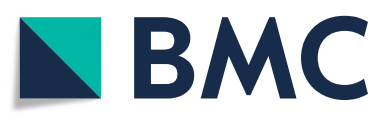

(c) The Author(s). 2021 Open Access This article is licensed under a Creative Commons Attribution 4.0 International License, which permits use, sharing, adaptation, distribution and reproduction in any medium or format, as long as you give appropriate credit to the original author(s) and the source, provide a link to the Creative Commons licence, and indicate if changes were made. The images or other third party material in this article are included in the article's Creative Commons licence, unless indicated otherwise in a credit line to the material. If material is not included in the article's Creative Commons licence and your intended use is not permitted by statutory regulation or exceeds the permitted use, you will need to obtain permission directly from the copyright holder. To view a copy of this licence, visit http://creativecommons.org/licenses/by/4.0/ The Creative Commons Public Domain Dedication waiver (http://creativecommons.org/publicdomain/zero/1.0/) applies to the data made available in this article, unless otherwise stated in a credit line to the data. 


\section{Background}

High-dose chemotherapy with autologous stem-cell transplantation (HDT-ASCT) is a potentially curative treatment option for selected lymphoma patients. It is associated with severe acute and late adverse effects. Potential late adverse effects include secondary cancers, cardiovascular disease, peripheral neuropathies, hormonal disturbances, chronic fatigue and mental distress [1], causing physical and mental strain, and challenging patients' work ability. Due to higher treatment-related mortality and morbidity with increasing age, HDTASCT is usually reserved for patients $<65-70$ years [2], and most lymphoma patients treated with HDT-ASCT are therefore within working age, with potentially numerous years left until retirement. Maintaining work ability and employment is thus an important issue not only for the individual survivor after HDT-ASCT but also for society as a whole. In a previous study, our group studied employment patterns and associated factors for this patient group [3]. We found psychosocial factors to be associated with labour market withdrawal at follow-up, but hardly any lymphoma-related variables. An extensive body of research relates to absenteeism in work life $[4,5]$, lending support to the hypothesis that (sickness) absence leads to more absence.

In this article, we describe work-related outcomes amongst lymphoma survivors treated with HDT-ASCT. We have access to data describing work life parameters for lymphoma survivors treated with HDT-ASCT before onset of illness, during and after treatment. From this material, we also study post-treatment work patterns and try to identify determinants for stable labour force participation and exclusion post treatment.

The aims of the present study are to:

1. Investigate factors affecting labour force participation in lymphoma survivors after HDTASCT.

2. Compare work ability and work hours for withdrawals (patients who were employed when diagnosed but not before HDT-ASCT) and nonwithdrawals.

3. Assess the economic loss of income related to withdrawal.

We postulate the following hypothesis using this dataset: Withdrawal from work life has a causal and negative effect on future work participation.

\section{Methods}

\section{Patients}

The data source is a national multicentre cross-sectional follow-up study where all survivors treated with HDTASCT for lymphoma in Norway between 1995 and 2008, aged $\geq 18$ years at HDT-ASCT, alive at survey, residing in Norway and currently not undergoing systemic therapy for active malignancy were eligible and invited to participate ( $n=355$, Fig. 1$)$. The survey, performed in 2012-2013, consisted of a detailed self-reported questionnaire with a set of well-established patient reported outcome measures $[3,6]$, a comprehensive out-patient clinical examination [7], as well as data retrieved from patients' charts and the clinical quality register for lymphoma at Oslo University Hospital (OUH). For the present study, we include only survivors treated with BEAM (carmustine, etoposide, cytarabine and melphalan), which has been the standard high-dose regimen in Norway since 1995, excluding six survivors treated with total body irradiation (TBI). In Norway, all citizens are entitled to old-age pension from 67 years of age. Respondents who reported receiving old-age pension $(n=40)$ or being students $(n=3)$ at survey are excluded in the present study since the focus here is on work patterns before and after treatment, and these two groups are not considered part of the formal labour force. In general, the survey had a low percentage of missing data.

\section{Treatment}

Survivors are categorized according to primary lymphoma entity: Hodgkin lymphoma (HL), indolent nonHodgkin lymphoma (NHL) and aggressive NHL, number of regimens prior to HDT-ASCT, and whether they experienced relapse after HDT-ASCT or not [3]. Body Mass Index (BMI) is from the clinical examination $(\mathrm{kg} /$ $\mathrm{m} 2$ ). We replaced 36 missing values using statistical measures based on self-reported BMI.

\section{Main outcomes}

Patients were asked to retrospectively report their employment status when first diagnosed and before HDTASCT, as well as their current work situation (at survey), according to eleven categories. We use this information to construct three categories for employment status; fulltime workers (having a fulltime job, being self-employed, or on sick leave), part-time workers (part-time job), or not employed (unemployment insurance, disability insurance, temporary disability insurance, or homemaker).

Patients rated their work ability on a scale of 1 to 10 (where 10 is best), both as they perceived it when answering the survey, and how they remembered it before onset of illness (i.e. when first diagnosed). They were also asked to report the number of weekly work hours at survey and when diagnosed. Their current employment status, current work hours and current work ability are the main outcomes in our analyses.

Based on their current work situation (at the time of survey), we construct a three-part categorical variable for employment; full-time workers, part-time workers 


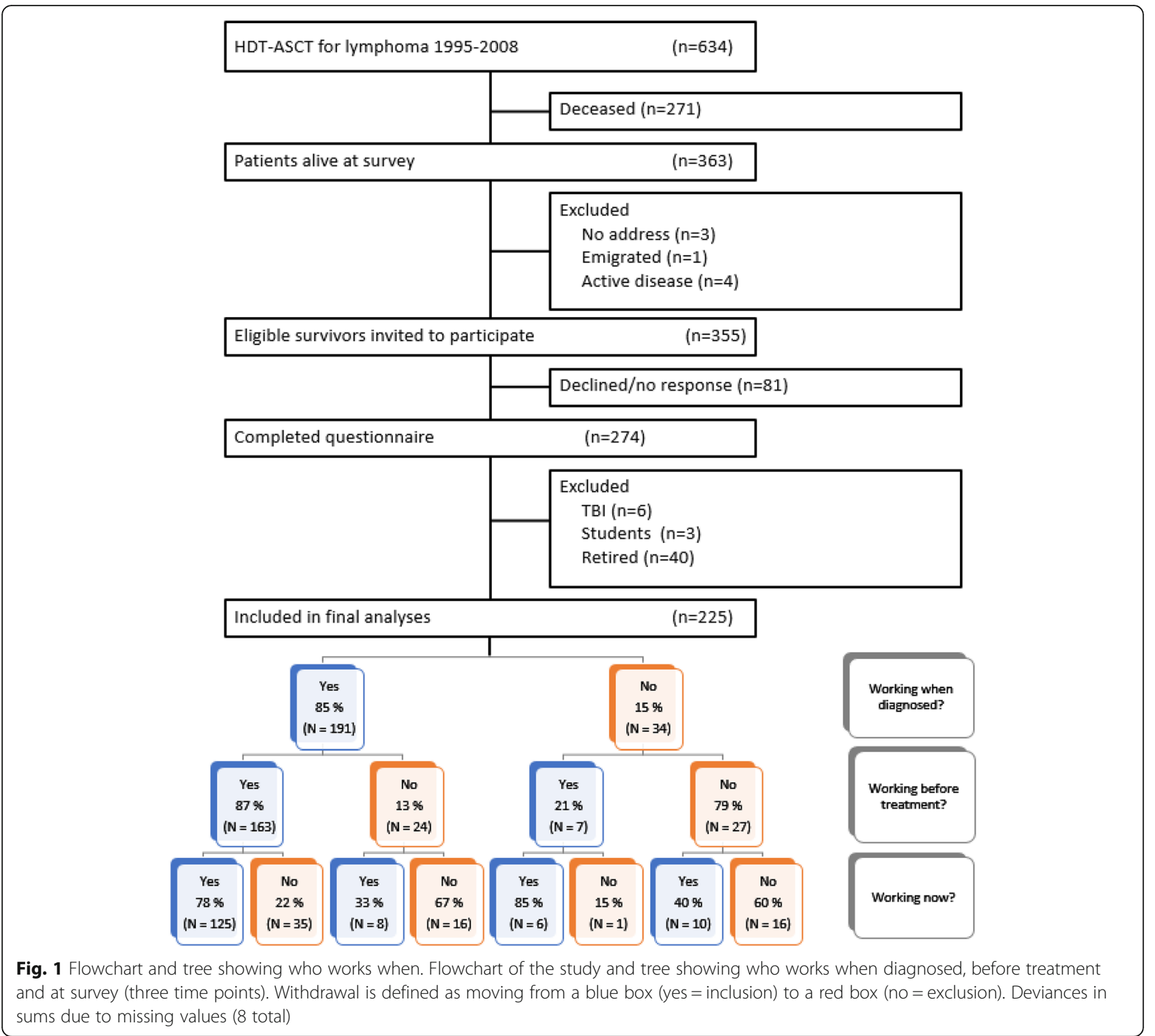

and not employed (Table 1), and a binary variable for being employed at follow-up (not distinguishing between full and part time) or not.

For these questions, we have used a modified version of the Work Ability Index (WAI) [8], and questions developed by our group in previous studies [3, 9].

\section{Withdrawal from work life}

We use the three questions that pin their employment status to three points in time (when diagnosed, before HDT-ASCT, and at survey) to create the tree shown in Fig. 1 to describe withdrawal from work life. We postulate that once you move from a blue box (inclusion) to a red box (exclusion) it is harder to return to a blue one. We refer to this as "withdrawal" from work life, conditioned on inclusion at the time of diagnosis, thus only defined for the left-hand side of the tree. Nonwithdrawals are the respondents on the left branch of the left-hand side of the tree (three positives, $n=125$ ).

\section{Pseudo panels for withdrawals and non-withdrawals}

We exploit the variation in time from when a patient received HDT-ASCT, until he or she completed the questionnaire. We construct three intervals: 3-7 years, 8-12 years and 13 years or more, of relatively equal size. We thus simulate panel data, creating 'pseudo panels' for current work hours and work ability, supplemented with work hours and work ability from when they were first diagnosed.

The term 'pseudo panel' refers to the fact that we do not have the opportunity to follow the same patients over time. Instead, we group respondents according to how 
Table 1 Descriptives

\begin{tabular}{|c|c|c|c|c|}
\hline Variable description & Total & Full-time workers & Part-time workers & Not employed \\
\hline $\mathbf{N}$ & 225 & 113 & 40 & 68 \\
\hline \multicolumn{5}{|l|}{ Current work situation (from questionnaire) } \\
\hline Background variables & Per cent & Per cent & & \\
\hline Female & 39 & 21 & 63 & 54 \\
\hline Married (missing $n=1$ ) & 74 & 72 & 73 & 75 \\
\hline \multirow[t]{2}{*}{ Higher education (missing $n=1$ ) } & 47 & 51 & 54 & 37 \\
\hline & Mean (sd) & Mean (sd) & & \\
\hline Age at diagnosis & $40(12.9)$ & $39(12.7)$ & $40(13.3)$ & $42(12.3)$ \\
\hline Age at treatment & $43(12.9)$ & $42(12.3)$ & $43(14.0)$ & $45(12.6)$ \\
\hline Age at questionnaire & $52(11.6)$ & $51(10.7)$ & $52(13.5)$ & $54(11.6)$ \\
\hline Body Mass Index & $26(4.9)$ & $26(4.0)$ & $26(6.0)$ & $26(5.6)$ \\
\hline Time: Diagnose to HDT-ASCT & $2.9(3.8)$ & $2.9(4.32)$ & $3.1(3.7)$ & $2.7(2.8)$ \\
\hline Time: HDT-ASCT to survey & $8.7(3.7)$ & $8.7(3.8)$ & $9.1(3.7)$ & $8.5(3.6)$ \\
\hline Labour market characteristics & Per cent & Per cent & & \\
\hline Employed at diagnosis & 85 & 89 & 90 & 75 \\
\hline Employed before HDT-ASCT (missing $n=4$ ) & 77 & 91 & 79 & 53 \\
\hline \multirow[t]{2}{*}{ Employed at survey (missing $n=4$ ) } & 69 & 100 & 100 & 0 \\
\hline & Mean (sd) & Mean $(s d)$ & & \\
\hline Work hours at diagnosis (missing $n=32$ ) & $34(13.3)$ & $36(12.2)$ & $34(11.0)$ & $31(14.6)$ \\
\hline Work hours if employed now & $21(18.6)$ & $34(12.6)$ & $21(12.8)$ & $0(0)$ \\
\hline Work ability at diagnosis (missing $n=20$ ) & $8.5(2.8)$ & $9.3(1.5)$ & $8.9(2.7)$ & $6.8(3.9)$ \\
\hline Work ability at survey (missing $n=26$ ) & $6.1(3.2)$ & $7.9(2.1)$ & $5.8(2.0)$ & $2.8(2.9)$ \\
\hline Health-related characteristics & Per cent & Per cent & & \\
\hline Heart disease (missing $n=1$ ) & 9 & 8 & 8 & 12 \\
\hline Second cancer & 11 & 7 & 10 & 19 \\
\hline Relapse after HDT-ASCT & 21 & 18 & 28 & 24 \\
\hline Chronic fatigue (missing $n=1$ ) & 33 & 21 & 43 & 49 \\
\hline Anxiety & 21 & 12 & 18 & 37 \\
\hline \multicolumn{5}{|l|}{ Lymphoma diagnose } \\
\hline$\triangleright$ Hodgkin's lymphoma & 27 & 28 & 25 & 26 \\
\hline$\triangleright$ Aggressive lymphoma & 65 & 65 & 70 & 62 \\
\hline$\triangleright$ Indolent lymphoma & 8 & 7 & 5 & 12 \\
\hline \multicolumn{5}{|l|}{ Treatment lines before HDT-ASCT } \\
\hline$\triangleright$ One & 28 & 33 & 23 & 21 \\
\hline$\triangleright$ Two & 59 & 54 & 63 & 65 \\
\hline$\triangleright$ More than two & 14 & 13 & 15 & 15 \\
\hline
\end{tabular}

Sample descriptives with sociodemographic and health variables and work-related characteristics. Deviancies due to missing values (of the 225 included in the final analyses, four had missing values for current work situation and could therefore not be categorised as full time, part time or not working). HDT-ASCT: Highdose chemotherapy with autologous stem-cell transplantation, sd: Standard deviation. Fulltime workers: Fulltime job (94) Self-employed (18) Sickleave (1). Parttime workers: (40). Not employed: unemployment insurance (2), disability insurance (50), temporary disability insurance (15), homemaker (1).

long it has been from the time they received treatment (HDT-ASCT) until they completed the questionnaire.

\section{Ratios for work hours and work ability}

We calculate ratios for work hours as work hours in the withdrawal group divided by work hours amongst those who stayed employed from diagnosis to survey, repeating the calculation for work ability.

\section{Economic loss}

We estimate an economic loss from the difference in work hours between the withdrawal group and the non- 
withdrawals using wage statistics from Statistics Norway (https://www.ssb.no/en/statbank/table/08057). We estimate an expected mean wage for the withdrawal group using monthly earnings (NOK) for 2012, covering all employees, matching them by gender and level of education.

\section{Explanatory variables}

We define marriage as being in a paired relationship, and higher education as more than 12 years of education. We construct two binary variables for somatic illnesses; one for having had one or more of three heart diseases (myocardial infarction, angina pectoris or heart failure), and another for second cancers (new cancer diagnosis, other than lymphoma). Chronic fatigue is assessed according to the Fatigue Questionnaire [10], containing 11 items concerning physical (7 items) and mental (4 items) fatigue during the last month. Two additional items cover duration and extent of fatigue. Responses are dichotomised ( 0 and 1 scored as 0 , and 2 and 3 scored as 1), with CF defined as sum score of $\geq 4$ of the dichotomised responses with duration of $\geq 6$ months. Anxiety is derived from the Hospital Anxiety and Depression Scale (HADS), consisting of an anxiety and a depression subscale with seven items each [11]. Each item is scored from 0 (not present) to 3 (highly present), and anxiety caseness is defined as a sum score of $\geq 8$ on the anxiety subscale.

\section{Statistical analyses}

We run a multinomial logistic regression, allowing for comparison between more than two groups (Table 2). The dependent variable was the categorical three-part variable divided into not working (base outcome), part time (work) and full time (work) at the time of survey. We include six covariates, relaxing the rule of thumb of 10 events per variable in logistic regression [12]. Employment before treatment is our main variable of interest. Gender and age at survey are necessary individual characteristics. We choose second cancers, chronic fatigue, and anxiety based on their significance in the regression models (Table 2) and their clinical relevance. Other covariates were tested, but they had limited explanatory power, and were not included in the proceeding analyses.

We run five regression models with the binary variable for employment (i.e. employed or not) at follow-up as the dependent variable, conditioned on being employed at diagnosis (Table 3). In model 1, employment before treatment is the sole covariate. We expand the model stepwise, adding new covariates in each step. In model 2, we include the sociodemographic variables gender, relationship status, education and age at survey. In model 3, we add the somatic health variables BMI, heart disease, second cancer and relapse of lymphoma. Next, we add the mental health variables chronic fatigue and anxiety (model 4). In model 5, we add the number of treatment lines before HDT-ASCT and lymphoma type.

Table 2 Results from multinomial logistic regression

\begin{tabular}{|c|c|c|c|c|}
\hline Variable description & Relative risk ratio & $\mathbf{z}$ & $p$-value & {$[95 \% \mathrm{Cl}]$} \\
\hline \multicolumn{5}{|c|}{ Not working at survey (base outcome) } \\
\hline \multicolumn{5}{|l|}{ Working part time at survey } \\
\hline Employed before HDT-ASCT & 4.17 & 2.82 & 0.005 & {$\left[\begin{array}{lll}1.54 & 11.27\end{array}\right]$} \\
\hline Female & 2.00 & 1.52 & 0.128 & [0.82 4.88] \\
\hline Age at survey & 0.98 & -1.28 & 0.200 & {$[0.941 .01]$} \\
\hline Second cancer & 0.39 & -1.45 & 0.148 & {$[0.111 .40]$} \\
\hline Chronic fatigue & 0.98 & -0.04 & 0.972 & {$\left[\begin{array}{lll}0.40 & 2.40\end{array}\right]$} \\
\hline Anxiety & 0.24 & -2.49 & 0.013 & {$\left[\begin{array}{lll}0.08 & 0.74\end{array}\right]$} \\
\hline Constant & -0.90 & -0.10 & 0.922 & {$[0.108 .23]$} \\
\hline \multicolumn{5}{|l|}{ Working full time at survey } \\
\hline Employed before HDT-ASCT & 9.57 & 4.66 & 0.000 & {$[3.7024 .78]$} \\
\hline Female & 0.34 & -2.68 & 0.007 & {$\left[\begin{array}{lll}0.15 & 0.74\end{array}\right]$} \\
\hline Age at survey & 0.95 & -3.02 & 0.003 & [0.92 0.98] \\
\hline Second cancer & 0.31 & -2.13 & 0.033 & {$\left[\begin{array}{lll}0.10 & 0.91]\end{array}\right]$} \\
\hline Chronic fatigue & 0.34 & -2.65 & 0.008 & {$\left[\begin{array}{lll}0.15 & 0.75\end{array}\right]$} \\
\hline Anxiety & 0.32 & -2.44 & 0.015 & {$\left[\begin{array}{ll}0.12 & 0.80\end{array}\right]$} \\
\hline Constant & 14.84 & 2.69 & 0.007 & [2.08 106.07] \\
\hline
\end{tabular}

Being employed before HDT-ASCT (high-dose chemotherapy with autologous stem-cell transplantation) increases probability of employment at survey, part or full time, compared to not being employed (base outcome). Cl Confidence Interval 
Table 3 Results from the five regression models

\begin{tabular}{|c|c|c|c|c|c|}
\hline Variable description & Model 1 & Model 2 & Model 3 & Model 4 & Model 5 \\
\hline N & 184 & 183 & 182 & 182 & 182 \\
\hline Employed at survey & Yes & Yes & Yes & Yes & Yes \\
\hline \multirow[t]{2}{*}{ Constant } & $0.333^{* * *}$ & $0.701^{* * *}$ & $0.812^{* *}$ & $0.955^{* * *}$ & $0.962^{* * *}$ \\
\hline & (3.85) & $(3.70)$ & $(3.20)$ & (3.79) & (3.71) \\
\hline \multirow[t]{2}{*}{ Employed before HDT-ASCT } & $0.448^{* * *}$ & $0.445^{* * *}$ & $0.436^{* * *}$ & $0.384^{* * *}$ & $0.373^{* * *}$ \\
\hline & $(4.83)$ & $(4.70)$ & $(4.62)$ & $(4.09)$ & $(4.00)$ \\
\hline \multirow[t]{2}{*}{ Female } & & -0.094 & -0.066 & -0.034 & -0.040 \\
\hline & & $(-1.43)$ & $(-1.00)$ & $(-0.52)$ & $(0.60)$ \\
\hline \multirow[t]{2}{*}{ Married } & & -0.125 & $-0.168^{*}$ & $-0.146^{*}$ & $-0.143^{*}$ \\
\hline & & $(-1.69)$ & $(-2.31)$ & $(-2.05)$ & $(-2.01)$ \\
\hline \multirow[t]{2}{*}{ Higher education } & & 0.040 & 0.073 & 0.054 & 0.072 \\
\hline & & $(0.63)$ & $(1.20)$ & $(0.90)$ & (1.18) \\
\hline \multirow[t]{2}{*}{ Age at survey } & & -0.005 & -0.004 & -0.005 & -0.004 \\
\hline & & $(-1.63)$ & $(-1.36)$ & $(-1.82)$ & $(-1.15)$ \\
\hline \multirow[t]{2}{*}{ Body Mass Index } & & & -0.005 & -0.004 & -0.006 \\
\hline & & & $(-0.71)$ & $(-0.57)$ & $(-0.91)$ \\
\hline \multirow[t]{2}{*}{ Heart disease } & & & 0.076 & 0.095 & 0.063 \\
\hline & & & $(0.66)$ & $(0.83)$ & $(0.55)$ \\
\hline \multirow[t]{2}{*}{ Second cancer } & & & $-0.444^{* * *}$ & $-0.410^{* * *}$ & $-0.474^{* * *}$ \\
\hline & & & $(-4.34)$ & $(-4.09)$ & $(-4.54)$ \\
\hline \multirow[t]{2}{*}{ Relapse } & & & 0.104 & 0.078 & 0.138 \\
\hline & & & $(1.30)$ & $(0.98)$ & $(1.65)$ \\
\hline \multirow[t]{2}{*}{ Chronic fatigue } & & & & $-0.126^{*}$ & -0.109 \\
\hline & & & & $(-1.93)$ & $(-1.65)$ \\
\hline \multirow[t]{2}{*}{ Anxiety } & & & & $-0.176^{*}$ & $-0.192^{*}$ \\
\hline & & & & $(-2.20)$ & $(2.40)$ \\
\hline \multicolumn{6}{|l|}{ Treatment lines } \\
\hline One & & & & & (base outcome) \\
\hline \multirow[t]{2}{*}{ Two } & & & & & 0.009 \\
\hline & & & & & $(0.13)$ \\
\hline \multirow[t]{2}{*}{ More than two } & & & & & -0.168 \\
\hline & & & & & $(-1.57)$ \\
\hline \multicolumn{6}{|l|}{ Lymphoma type } \\
\hline Hodgkin & & & & & (base outcome) \\
\hline \multirow[t]{2}{*}{ Aggressive } & & & & & -0.008 \\
\hline & & & & & $(0.09)$ \\
\hline \multirow[t]{2}{*}{ Indolent } & & & & & -0.143 \\
\hline & & & & & $(-1.12)$ \\
\hline Variation in model explained (\%) & 0.11 & 0.15 & 0.23 & 0.28 & 0.30 \\
\hline
\end{tabular}

Statistics: Each coefficient shows how the probability of employment at survey relates to the various covariates $\left({ }^{*} p<0.05 ; * * p<0.01 ;{ }^{* * *} p<0.001 ; t\right.$-values in parentheses).

Employment before treatment, conditioned on being employed at onset, stays significant throughout all five regression models $\left(^{*} p<0.05 ;{ }^{* *} p<0.01 ;{ }^{* * *} p<\right.$ 0.001; $\mathrm{t}$-values in parentheses). HDT-ASCT $=$ high-dose chemotherapy with autologous stem-cell transplantation. 
We use a standard t-test to test whether the difference in means between withdrawals' and non-withdrawals' work hours and work ability at more than 13 years is different from the difference in means at onset. We restrict the test to the patients observed at diagnosis and 13 years or more after treatment. We test the null hypothesis, that there is no difference in means.

We exclude respondents with missing observations from the analyses when the relevant variable enters the equation. Despite a somewhat higher incidence of missing values for work hours and work ability, we choose not to use statistical measures to replace them, considering the risk of manipulating the results too great. We do not have additional information (as we did for BMI), which could be used to estimate missing values, and would therefore have to rely on imputations based on other respondents' values.

\section{Ethics}

The South-East Regional Committee for Medical and Health Research Ethics (REC South East) approved the study, and all participants gave written informed consent.

\section{Results}

\section{Attrition analysis}

There are no differences between the participants and non-participants with regard to age at diagnosis, HDTASCT or survey, nor gender, observation time or lymphoma entity.

\section{Patient characteristics}

In total, 274 survivors completed the questionnaire (77\% of eligible survivors), 49 were excluded, leaving 225 respondents for the final analyses (Fig. 1).

In total, $39 \%$ of the participants are female, $74 \%$ are in a paired relationship, and $47 \%$ have higher education. Their mean age was 40, 43 and 52 years at diagnosis, HDT-ASCT, and survey, respectively (Table 1 ).

Labour market characteristics show that $85 \%$ of the participants were employed when diagnosed. They worked on average $34 \mathrm{~h}$ per week. On a scale of 1 to 10 , their work ability averaged 8.5. At the time of the survey, median 10.8 years later, $69 \%$ were employed, they worked $21 \mathrm{~h}$ per week, and their work ability was 6.1 (Table 1). The 99\% confidence intervals show no overlap for the respective means.

\section{Factors associated with being employed at survey}

Results from the multinomial logistic regression model show that being employed before HDT-ASCT increases the probability of employment at survey, part or full time, compared to not being employed (base outcome) (Table 2). The other covariates; female gender, higher age, diagnosed with second cancers, chronic fatigue and anxiety; reduce the probability of working full time at survey (coefficients $<1$ ), while anxiety reduces the probability of working part time.

\section{Employment before HDT-ASCT positively correlated with later employment}

The main result from the five regression models (Table 3 ) is that employment before HDT-ASCT is significantly and positively correlated with employment at survey throughout all five models. The constant in model 1 predicts a $33 \%$ probability of being employed at survey if not employed before HDT-ASCT, whereas being employed before HDT-ASCT adds 44.8 percentage points to this probability. In models two to five, employment before HDT-ASCT adds 44.5, 43.6, 38.4, and 37.3 percentage points, respectively.

Three covariates; second cancers, anxiety, and being in a paired relationship; are associated with a lower probability of employment at follow-up. Results from the most extensive model (5) suggest that getting a second cancer diagnosis reduces the probability of employment at survey by 47.4 percentage points. Anxiety is associated with a reduction in this probability of 19.2 percentage points, while being in a paired relationship is associated with a reduction of 14.3 percentage points. The remaining health variables have no significant effect on the probability of future employment.

\section{Withdrawal versus non-withdrawal group}

In Fig. 2 (the top two panels), we show trajectories for the pseudo panels for work hours and work ability for non-withdrawals and withdrawals; at diagnosis, their average reported weekly work hours were 38.2 and 34.5, respectively, similar to a regular workweek $(37.5 \mathrm{~h})$. Non-withdrawals rated their work ability at 9.2, while withdrawals rated theirs at 7.6, on average. After HDTASCT, average weekly work hours in the withdrawal group drop to 7.1 amongst those who answered the survey 3-7 years later. In the group who responded 8-12 years later, it drops to 1.1 , while it is 0 for those responding $\geq 13$ years after HDT-ASCT. The drop in work hours for non-withdrawals is smaller, and stabilises at 30.5. Withdrawals' reported work ability at survey is 2.9 for those who respond 3-7 years after HDT-ASCT, and 3 for those who respond 8-12 years later. However, for those who respond more than 12 years later, it is 5.1. Work ability for non-withdrawals drops steadily to 7.5 , 7.1 and 7. The trajectory for work ability in the withdrawal group suggests a rebound effect over time.

\section{Different trajectories: testing differences in means}

We amplify the differences in trajectories for withdrawals and non-withdrawals in the last panel in Fig. 2. At 


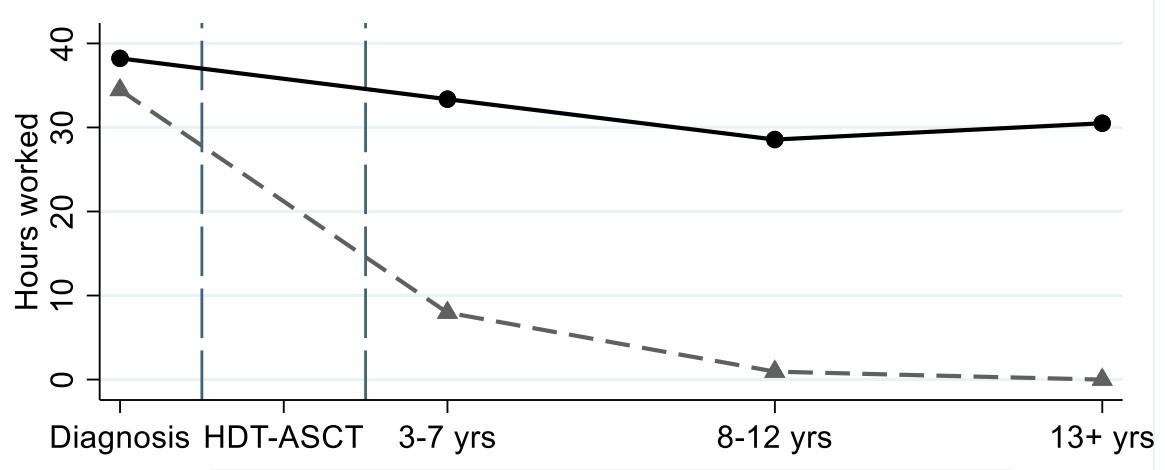

$\longrightarrow$ Always employed $\quad-\rightarrow--$ Withdrawal
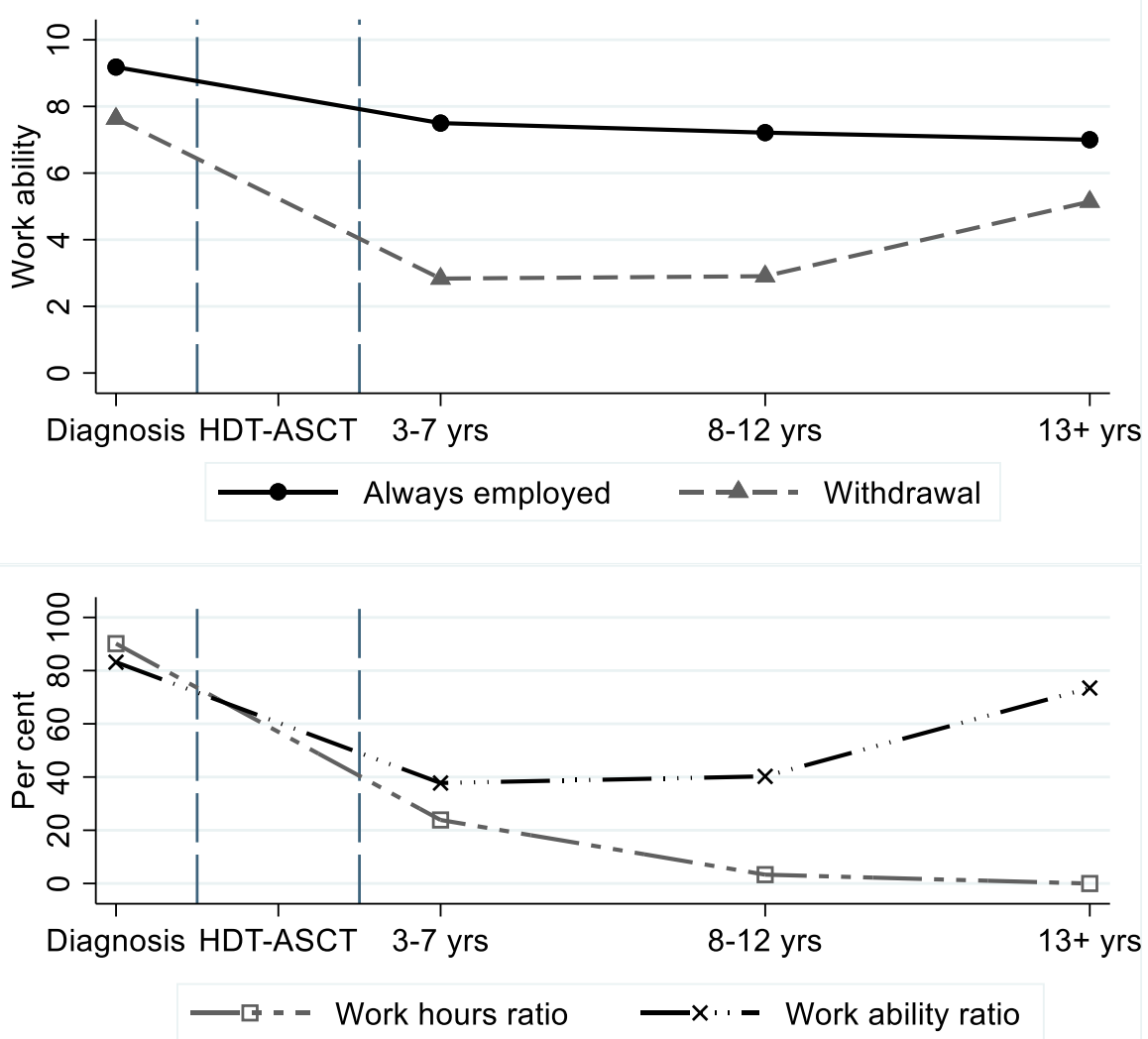

Time from primary diagnosis to survey

Fig. 2 Pseudo panels for work hours and work ability. The two upper panels show pseudo panels for work hours and work ability, for withdrawals and non-withdrawals (always employed). Last panel shows rebound effect for withdrawals' work ability but not for their work hours. Ratios estimated as withdrawals' work ability (work hours) as share of non-withdrawals' work ability (work hours) from diagnose to survey

diagnosis, work hours and work ability in the withdrawal group were around 90 and $80 \%$ of non-withdrawals', respectively, but, while withdrawals' work hours drop to zero, work ability rebounds to a level similar to where it started 13 years or more after treatment (Fig. 2). The difference in average weekly work hours between withdrawals and non-withdrawals is $-5.4 \mathrm{~h}$ at diagnosis, compared to $-29.4 \mathrm{~h} 13$ years or more after treatment $(\operatorname{Pr}(|\mathrm{T}|>|\mathrm{t}|)=0.0001)$. However, there is no statistically significant difference in average work ability (2.6 points lower in the withdrawal group at diagnosis, and 4 points lower after 13 years $(\operatorname{Pr}(|\mathrm{T}|>|\mathrm{t}|)=0.265))$. 


\section{Economic loss estimation}

The withdrawal group works on average $26.6 \mathrm{~h}$ less per week than non-withdrawals at survey. Using wage statistics for 2012 (year of survey start) from Statistics Norway, by gender and level of education, we estimate an expected mean hourly wage of NOK 265.40. This gives us a yearly loss per person of NOK 331,555 (EUR 34,791 ), equivalent to $70 \%$ of the average yearly wage in Norway in 2012 of NOK 470,900 (Statistics Norway).

\section{Discussion}

Our data suggest a strong correlation between withdrawing from the labour market during illness and future labour market prospects, even when controlling for an extensive set of health variables. This brings us back to our introductory hypothesis: Withdrawal from work life has a causal and negative effect on future work participation. If our hypothesis holds true, there should be little or no change in the coefficient for employment before treatment (i.e. the opposite of withdrawal) as we expand the regression model with sociodemographic and healthrelated variables, and it should stay significant. This is precisely what we find. Thus, staying employed throughout diagnosis and treatment implies a consistently higher probability of future employment, regardless of symptom burden.

Our results are similar to other researchers' findings on absenteeism; (sickness) absence leads to more absence, while being present (at work) promotes work participation. Studies using Norwegian administrative data, covering the whole population, show that compulsory dialogue meetings for long-term sickleave absentees reduced absence duration considerably [5]. Graded (instead of fulltime) sickleave had a similar effect, leading to shorter absence and higher subsequent employment rates [4]. The policy implications could be measures that promote inclusion throughout periods of illness and treatment, such as activity requirements [4].

Few studies have explored work life issues in longterm lymphoma survivors. A Danish registry-based study reported an increased risk of disability pension among survivors of haematological malignancies (including lymphoma) compared to the reference cohort [13]. In the patient cohort, comorbidity and need of treatment with anxiolytics and antidepressants after diagnosis were associated with disability pension. This is comparable with our findings of significant association with anxiety and employment, and in line with a previous study by our group among young adult cancer survivors of different diagnoses, where late adverse effects and other health-related factors were negatively associated with work life issues [9]. A qualitative study among selfemployed cancer survivors, also found that late effects limited their work ability following treatment [14]. These findings emphasize the importance of addressing and initiating treatment and rehabilitation for late effects among cancer survivors in order to maintain work ability and function. A recent review concluded that multidisciplinary outpatient cancer rehabilitation might affect cancer patients' physical and psychosocial status. However, they pointed to the need for more research on long-term outcomes, such as effects on return to work [15].

These findings implicate a need for both health care workers and those working in the welfare system to be aware of late effects after cancer as factors associated with reduced work life participation. Interventions aiming at improving late effects after cancer are strongly needed, and might improve work participation in the long term.

Work hours and work ability decrease for both withdrawals and non-withdrawals from diagnosis, through treatment, until survey when the participants receive the questionnaire. However, whereas both work ability and work hours amongst non-withdrawals stabilise relatively quickly at a modestly lower level, the trajectories are different for those who withdraw from the labour market. Their work hours drop below 10 in the first years after HDT-ASCT and continue to fall. A decade later, they hardly work at all. Work ability also drops but the initial fall is smaller, and the trajectory suggests a catch-up effect 13 years or more after treatment. The question arises: Is the difference in work ability between these two groups 13 years after HDT-ASCT identical to the difference that already existed at the time of diagnosis? And can the same be said for work hours? Does their withdrawal from work life stem not from lack of ability, but from lack of possibility?

Results from the standard t-test allow us to reject the null hypothesis for work hours, but not for work ability. We cannot conclude, on any conventional level of significance, that the difference in work ability 13 or more years after treatment is different from the difference in means that already existed at diagnosis, whereas for work hours it is highly significant. The ratios in Fig. 2 (last panel) illustrate this; while work ability for the withdrawal group starts just above $80 \%$, drops to $40 \%$, and rebounds to a level slightly below $80 \%$ of nonwithdrawals' work ability, their work hours drop from 90 to $0 \%$ of non-withdrawals'.

If anything, we expect work ability to be underreported for respondents outside the labour force, due to self-justification bias, i.e. they under-report their work ability to justify their exclusion [16]. Thus, we consider the gap between work ability and employment a lower bound.

Work hours in the withdrawal group does not reflect the catch-up effect in work ability. Assuming we could 
avoid their withdrawal, what is the potential gain from re-entering these patients into the labour force? Our estimations suggest a yearly loss of NOK 331,555 (EUR 34, 791 ), equivalent to $70 \%$ of the average yearly wage in Norway in 2012 (Statistics Norway). Avoiding withdrawal and its subsequent effects could represent a substantial gain, not only for those directly affected but also for society as a whole.

\section{Norwegian labour market characteristics}

Compared to other European countries, Norway has a relatively high employment rate. On the other hand, a relatively high share of the working-age population receives health-related benefits [17]. Work force participation depends on individual characteristics, such as education and work ability, but also on labour market regulations and the income insurance system.

\section{Strengths and limitations}

Strengths of this study include the completeness and representativeness of the study population, with all lymphoma survivors after HDT-ASCT in Norway being accounted for, together with the high response rate of $77 \%$. Furthermore, participants and non-participants are highly comparable, strengthening the generalisability of our results.

Our study is limited by the cross-sectional design preventing any conclusion regarding causality to be made. All work-related data were collected by questionnaire at one time point, with a risk for recall bias, and not controlled by interviews and/or data from The Norwegian Work and Welfare Administration.

\section{Conclusion}

In this national study, we find that Norwegian lymphoma survivors have a higher probability of employment after treatment with HDT-ASCT if staying employed throughout diagnose and treatment. Our results support the hypothesis that withdrawal from the labour market has a negative effect on future labour market participation, even as we control for an extensive set of health variables. Thus, for a given symptom burden, withdrawal negatively affects employment later in life.

\section{Abbreviations \\ BEAM: Carmustine, etoposide, cytarabine and melphalan; BMI: Body Mass Index; EUR: Euros; HADS: Hospital Anxiety and Depression Scale; HDT- ASCT: High-dose chemotherapy with autologous stem-cell transplantation; HL: Hodgkin lymphoma; NHL: Non-Hodgkin lymphoma; NOK: Norwegian kroner; OUH: Oslo University Hospital; REC South East: Regional Committee for Medical and Health Research Ethics of South-East Norway}

\section{Acknowledgements}

We would like to thank Simen Markussen for his contribution to the concept of the article and statistical advice. We would also like to thank Hanne Bersvendsen and Øystein Fluge. Kjersti Helene Hernæs $(\mathrm{KHH})$ would like to thank her former employer, Oslo University Hospital, where most of the work took place.

\section{Authors' contributions}

$\mathrm{KHH}$ contributed with the concept for the article, analysed and interpreted the data, made figures and tables, and wrote the main body of the manuscript. Knut B. Smeland (KBS) contributed with conception and design of the study, collection and assembly of data, data analysis and interpretation, flowchart, attrition analysis and manuscript writing. Cecilie E. Kiserud (CEK) contributed with conception and design of the study, collection and assembly of data, data analysis and interpretation, and manuscript writing. Unn-Merete Fagerli (UMF) contributed with collection and assembly of data. All authors read and approved the final manuscript.

\section{Funding}

The South-Eastern Norway Regional Health Authority (Grant number 2011098 and 2011036) funded the project. They had no role other than funding.

\section{Availability of data and materials}

The datasets used and/or analysed during the current study are available from the corresponding author on reasonable request.

\section{Ethics approval and consent to participate}

The Regional Committee for Medical and Health Research Ethics of SouthEast Norway approved the study, including permission to access the raw data used in the study to source the participants. (2011/1353B). Informed consent was obtained from all individual participants included in the study. This article does not contain any studies with animals performed by any of the authors.

\section{Consent for publication}

Not applicable.

\section{Competing interests}

$\mathrm{KHH}$ declares that she has no conflict of interest. KBS declares that he has no conflict of interest. UMF has been on the Advisory Board for Roche and Takeda but declares that she has no conflict of interest in this study. CEK declares that she has no conflict of interest.

\section{Author details}

${ }^{1}$ Norwegian Institute of Public Health, PO Box 222, Skøyen, N-0213 Oslo, Norway. ${ }^{2}$ National Advisory Unit for Late Effects after Cancer Treatment, Oslo University Hospital, Radiumhospitalet, PO 4953, Nydalen, N-0424 Oslo, Norway. ${ }^{3}$ Department of Oncology, St. Olavs hospital HF, Postboks 3250 Torgarden, 7006 Trondheim, Norway. ${ }^{4}$ Institute for Clinical and Molecular Medicine (IKOM), The Norwegian University of Science and Technology (NTNU), Olav kyrres gate 9, 7006 Trondheim, Norway. ${ }^{5}$ Previous affiliation: Research Support Services, Oslo University Hospital, Sogn Arena, Klaus Torgårds vei 3, 3. Floor, 0372 Oslo, Norway.

Received: 25 August 2020 Accepted: 26 January 2021

Published online: 08 February 2021

\section{References}

1. Majhail NS, Ness KK, Burns LJ, Sun CL, Carter A, Francisco L, et al. Late effects in survivors of Hodgkin and non-Hodgkin lymphoma treated with autologous hematopoietic cell transplantation: a report from the bone marrow transplant survivor study. Biol Blood Marrow Transplant. 2007;13(10): 1153-9.

2. Smeland K, Kiserud C, Lauritzsen G, Blystad A, Fagerli U, Fluge $\varnothing$, et al. Highdose therapy with autologous stem cell support for lymphoma in Norway 1987-2008. Tidsskr Nor Laegeforen. 2013;133(16):1704-9.

3. Kiserud C, Fagerli U, Smeland K, Fluge $\varnothing$, Bersvendsen H, Kvaløy S, et al. Pattern of employment and associated factors in long-term lymphoma survivors 10 years after high-dose chemotherapy with autologous stem cell transplantation. Acta Oncol. 2016:55(5):547-53.

4. Markussen S, Mykletun A, Røed K. The case for presenteeism-evidence from Norway's sickness insurance program. J Public Econ. 2012;96(11-12): 959-72. 
5. Markussen S, Røed K, Schreiner RC. Can compulsory dialogues nudge sicklisted workers back to work? Econ J. 2017;128(610):1276-303.

6. Smeland KB, Loge $\mathrm{JH}$, Aass HC, Aspelin T, Bersvendsen H, Bolstad N, et al. Chronic fatigue is highly prevalent in survivors of autologous stem cell transplantation and associated with IL-6, neuroticism, cardiorespiratory fitness, and obesity. Bone Marrow Transplant. 2019;54(4):607.

7. Murbraech K, Smeland KB, Holte H, Loge JH, Lund MB, Wethal T, et al. Heart failure and asymptomatic left ventricular systolic dysfunction in lymphoma survivors treated with autologous stem-cell transplantation: a national crosssectional study. J Clin Oncol. 2015;33(24):2683-91.

8. Tuomi K, Ilmarinen J, Jahkola A, Katajarinne L, Tulkki A. Work ability index: Finnish Institute of Occupational Health Helsinki; 1998.

9. Dahl AA, Fosså SD, Lie HC, Loge JH, Reinertsen KV, Ruud E, et al. Employment status and work ability in long-term young adult cancer survivors. J Adolesc Young Adult Oncol. 2019:8(3):304-11.

10. Chalder T, Berelowitz G, Pawlikowska T, Watts L, Wessely S, Wright D, et al. Development of a fatigue scale. J Psychosom Res. 1993;37(2):147-53.

11. Zigmond AS, Snaith RP. The hospital anxiety and depression scale. Acta Psychiatr Scand. 1983;67(6):361-70.

12. Vittinghoff $E$, McCulloch CE. Relaxing the rule of ten events per variable in logistic and cox regression. Am J Epidemiol. 2007;165(6):710-8.

13. Horsboel TA, Nielsen CV, Andersen NT, Nielsen B, de Thurah AJAO. Risk of disability pension for patients diagnosed with haematological malignancies: a register-based cohort study. Acta Oncol. 2014;53(6):724-34.

14. Torp S, Brusletto B, Withbro TB, Nygaard B, LJJoOR S. Work experiences during and after treatment among self-employed people with cancer. J Occup Rehabil. 2020;30(1):49-58.

15. Kudre D, Chen Z, Richard A, Cabaset S, Dehler A, Schmid M, et al. Multidisciplinary outpatient Cancer rehabilitation can improve Cancer patients' physical and psychosocial status-a systematic review. Curr Oncol Rep. 2020;22(12):1-17.

16. Black N, Johnston DW, AJJohe S. Justification bias in self-reported disability: New evidence from panel data. J Health Econ. 2017;54:124-34.

17. Øien-Ødegaard C, Reneflot A, Hauge LJ. Use of primary healthcare services prior to suicide in Norway: a descriptive comparison of immigrants and the majority population. BMC Health Serv Res. 2019;19(1):508.

\section{Publisher's Note}

Springer Nature remains neutral with regard to jurisdictional claims in published maps and institutional affiliations.

Ready to submit your research? Choose BMC and benefit from:

- fast, convenient online submission

- thorough peer review by experienced researchers in your field

- rapid publication on acceptance

- support for research data, including large and complex data types

- gold Open Access which fosters wider collaboration and increased citations

- maximum visibility for your research: over $100 \mathrm{M}$ website views per year

At $\mathrm{BMC}$, research is always in progress.

Learn more biomedcentral.com/submissions 